\title{
Does Strict Adherence to the Ponseti Method Improve Isolated Clubfoot Treatment Outcomes? A Two-institution Review
}

\author{
Nancy H. Miller MD, Patrick M. Carry BA, Bryan J. Mark BA, \\ Glenn H. Engelman BA, Gaia Georgopoulos MD, Sue Graham PA-C, \\ Matthew B. Dobbs MD
}

Received: 4 March 2015 / Accepted: 3 September 2015/Published online: 22 September 2015

(C) The Association of Bone and Joint Surgeons (B) 2015

\begin{abstract}
Background Despite being recognized as the gold standard in isolated clubfoot treatment, the Ponseti casting method has yielded variable results. Few studies have directly compared common predictors of treatment failure between institutions with high versus low failure rates.

Questions/purposes We asked: (1) is the provider's rigid adherence to the Ponseti method associated with a lower likelihood of unplanned clubfoot surgery, and (2) at the institution that did not adhere rigidly to Ponseti's principles, are any demographic or treatment-related factors associated with increased likelihood of unplanned clubfoot surgery?

Methods After institutional review board approval, a consecutive series of patients with a diagnosis of isolated clubfoot who underwent treatment between January 2003 and December 2007 were identified. At Institution 1, 91 of
\end{abstract}

The institution of one or more of the authors (NHM, PMC, GHE, GG, SG) has received, during the study period, funding from the Research Institute of Children's Hospital Colorado. One of the authors certifies that he (MBD), or a member of his or her immediate family, has received or may receive payments or benefits, during the study period, an amount of less than 10,000 USD, from D-Bar Enterprises (St Louis, MO, USA).

All ICMJE Conflict of Interest Forms for authors and Clinical Orthopaedics and Related Research ${ }^{\circledR}$ editors and board members are on file with the publication and can be viewed on request.

Clinical Orthopaedics and Related Research ${ }^{\mathbb{B}}$ neither advocates nor endorses the use of any treatment, drug, or device. Readers are encouraged to always seek additional information, including FDA approval status, of any drug or device before clinical use.

Each author certifies that his or her institution approved or waived approval for the human protocol for this investigation and that all investigations were conducted in conformity with ethical principles of research.

This study was conducted at Children's Hospital, Aurora, CO, USA and St. Louis Children's Hospital, St. Louis, MO, USA.
133 patients met the eligibility criteria and were followed for a minimum of 2 years compared with 58 of 58 patients at Institution 2. At Institution 1, 16 providers managed care using a conservative casting approach based on the Ponseti method. However, treatment was adapted by the provider(s). At Institution 2, one orthopaedic surgeon managed care with strict adherence to the Ponseti method. Surgical indications at both institutions included the presence of a persistent equinovarus foot position while standing. A chart review was used to collect data related to proportion of patients undergoing unplanned additional treatment for deformity recurrences after Ponseti casting, demographics, and treatment patterns.

Results The proportion of subjects who underwent unplanned major surgical intervention was greater (odds ratio [OR], 51.1; 95\% CI, 6.8-384.0; p < 0.001) at Institution 1 (60 of 131, 47\%) compared with Institution 2 (two of 91,

Electronic supplementary material The online version of this article (doi:10.1007/s11999-015-4559-4) contains supplementary material, which is available to authorized users.

N. H. Miller ( $₫)$, P. M. Carry, B. J. Mark, G. H. Engelman, G. Georgopoulos, S. Graham

Musculoskeletal Research Center, Department of Orthopaedic Surgery, Children's Hospital Colorado, 13123 East 17th Avenue, B600, Aurora, CO 80045, USA

e-mail: Nancy.Miller@ChildrensColorado.org

M. B. Dobbs

Washington University School of Medicine, St. Louis, MO, USA 
$2 \%)$. There was no difference $(\mathrm{p}=0.200)$ in the proportion of patients who underwent additional casting, repeat tendo Achilles lengthening, and/or anterior tibialis tendon transfer only (minor recurrence) at Institution 1 (nine of 131, $7 \%)$ compared with Institution 2 (11 of 91, 13\%). At Institution 1 , an increase in the number of revision casts (multiple vs no casts, hazard ratio $[\mathrm{HR}]=3.9 ; 95 \% \mathrm{CI}, 2.0$ 7.6; $\mathrm{p}<0.001)$ and an increase in the number of castrelated complications (multiple vs no complications, $\mathrm{HR}=$ $2.8 ; 95 \% \mathrm{CI}, 1.2-6.7 ; \mathrm{p}=0.019)$ were associated with increased risk of major surgery in the multivariate analysis. Conclusions Rigid commitment to the Ponseti method in the conservative treatment of patients with isolated clubfoot was associated with a lower risk of subsequent unplanned surgical intervention. In addition, clubfoot treatment programs that use a care model that prioritizes continuity in care and dedication to the Ponseti method may decrease the proportion of patients who undergo unplanned surgical intervention.

Level of Evidence Level III, therapeutic study.

\section{Introduction}

Talipes equinovarus, or "isolated clubfoot," occurs in 0.56 per 1000 births [19]. If untreated, this compromised foot position can result in long-term pain and severe disability [3, 9]. Conservative treatment attempts to correct the deformity such that the foot is functional, pain-free, flexible, and able to fit in regular shoes [22, 23]. The Ponseti method has become the gold standard in isolated clubfoot care $[7,20,25]$. This approach consists of specific serial manipulations, casting and tenotomy of the Achilles tendon, followed by abduction bracing of the affected foot or feet until the child is 2 to 4 years old. Minor relapses are treated with additional casting, repeat Achilles tenotomies, and/or anterior tibialis tendon transfers. Major recurrences, often regarded as treatment failure, require more extensive soft tissue release surgeries [7].

Conservative management of the clubfoot did not become accepted until the publication of Ponseti's treatise [23] and Internet popularization of the method. The Ponseti technique has been reported to yield successful rates without significant surgical events in upward of $95 \%$ of patients $[21,27]$. Although proponents of the Ponseti technique have reported it is "easy to learn" [29], costeffective [13], and results in better long-term function compared with surgical intervention [1, 15, 16, 33], Ponseti noted that strict adherence to his fundamental principles were essential for success [23]. Based on the comparison of a group of clubfeet treated with the Ponseti method to a historical control group treated with traditional conservative casting methods, Herzenberg et al. [15] reported that traditional conservative casting techniques were more likely to result in incomplete clubfoot correction. Despite the evidence, some centers have implemented variations of the Ponseti technique with less than optimal results, including the likelihood of converting to a surgical approach, ranging from $10 \%$ to $40 \%$ [5, 12, 14, 32]. Direct comparisons of treatment success between multiple pediatric institutions, to our knowledge, have not been done.

The purpose of this multisite, retrospective chart review was to compare the likelihood of unplanned major surgical interventions at two pediatric centers, an institution committed to the Ponseti method and an institution that did not rigidly adhere to the Ponseti method. We aimed to answer the primary questions: (1) Is the provider's rigid adherence to the Ponseti method associated with a lower likelihood of unplanned clubfoot surgery? (2) At the institution that did not adhere rigidly to Ponseti's principles, are any demographic or treatment-related factors associated with increased likelihood of unplanned clubfoot surgery?

\section{Methods}

A multisite, retrospective chart analysis was used to compare isolated clubfoot treatment patterns at two pediatric centers. After institutional review board approval, a consecutive series of patients were identified through an ICD-9 code search of patients with isolated clubfoot who began treatment between January 2003 and December 2007 and were followed for a minimum of 2 years after initiation of casting. Patients were excluded on the basis of nonisolated clubfoot, less than 2 years followup, treatment initiated at an outside hospital, and/or initial treatment delayed for more than 2 weeks from birth. All patients included in the study underwent planned conservative management. At Institution 1, 91 of 133 patients met the eligibility criteria and were followed for a minimum of 2 years compared with 58 of 58 patients at Institution 2. The charts of all eligible subjects at Institution 1 (91 patients, 131 feet) and Institution 2 (58 patients, 91 feet) were retrospectively reviewed, and variables related to the demographics of the subjects (sex, family history, complications during perinatal period) were collected. The number of providers involved in treatment and the characteristics of the providers (mid-level vs surgeon) also were collected. For the purpose of minimizing assessment bias, all data collection procedures at both institutions were performed by individuals (GH and PC) who were not involved in the clinical care of the patients.

Treatment-related variables were collected from two intervals of interest-the casting treatment period and the bracing treatment period. Variables collected during the casting period included average time (in days) between 
consecutive cast visits, number of cast visits in which a cast-related complication was documented (skin infection, subject intolerance, pain/irritation, wet cast, cast slippage, erythema, swelling of toes, skin breakdown, subject physically kicked off cast, and/or caregiver removed cast early), total number of different providers who performed castings per eligible limb during the casting period, proportion of casts performed by mid-level provider(s), and whether the subject underwent a percutaneous tenotomy. Variables collected during the bracing period included number of bracing-related visits, and number of bracing-related clinical visits in which noncompliance was documented (parent self-reported that patient was not wearing brace for the prescribed amount of time).

\section{Comparison of Institutions}

Institution 1 is a large tertiary children's hospital serving a metropolitan area with an estimated county population of 663,862 in 2014 [30]. Care at Institution 1 was managed through 16 different providers (10 fellowship-trained, pediatric orthopaedic surgeons and six pediatric orthopaedic midlevel providers) to accommodate patient preferences in terms of time, location, and convenience of appointments. The providers used a conservative casting approach based on the Ponseti method, with substantial variability in technique among providers. Treatment variations included alternative cast manipulations, taping, short leg orthotics, varying cast materials, "breaks" in casting treatment as desired by parents and/or secondary to skin complications, and selective use of percutaneous tendo Achilles lengthening procedures. Postcast bracing was common, but was not universal. Institution 2 consisted of a tertiary children's hospital and a Shriner's hospital, both located in a metropolitan area with an estimated county population of 1,001,876 in 2014 [30]. At Institution 2, care was managed by one orthopaedic surgeon (MD) dedicated to the Ponseti method for isolated clubfoot treatment. The method of treatment at Institution 2 consisted of rigid adherence to sequential plaster casting, visits for manipulation, and selective use of percutaneous tendo Achilles lengthening procedures. The process was followed by longterm bracing with periodic followups. The goal of treatment at both institutions was to achieve a pain-free, plantigrade foot. Surgical indications at both institutions included the presence of a persistent equinovarus foot while standing that was recalcitrant to casting and manipulation.

We compared the demographics and treatment patterns at the two institutions (Table 1). The proportion of parents who reported English was not their first language $(\mathrm{p}<$ $0.001)$, average birth weight of patients $(p=0.003)$, proportion of parents who self-reported being noncompliant with bracing recommendations $(\mathrm{p}<0.001)$, average number of casts during the initial casting period $(\mathrm{p}<$ $0.001)$, cast-related complications ( $\mathrm{p}<0.001)$, and average time between consecutive cast visits $(p=0.002)$ was greater at Institution 1 compared with Institution 2 . The proportion of patients who underwent a tenotomy $(\mathrm{p}<$ 0.001 ) was lower at Institution 1 compared with Institution 2 .

Primary Endpoint: Definition of Treatment Failure

Unplanned deviations from routine postcasting followup care were the primary outcome variables of interest. A minor recurrence was defined as a recurrence of deformity that was treated with repeat casting and/or revision tendo Achilles lengthening and/or anterior tibialis tendon transfer. Major surgery was defined as the occurrence of more extensive surgery (extensive soft tissue release) beyond repeat tendo Achilles lengthening and/or tendon transfer.

\section{Statistical Analysis}

Demographics and clinical characteristics of all patients were summarized using descriptive statistics. Continuous covariates that did not follow a normal distribution (number of cast complications and number of revision casts) were categorized in discrete groups (none; one vs multiple). A generalized logistic regression analysis was used to compare treatment outcomes between the institutions. Generalized logistic regression analyses were similarly used to compare patient demographics and treatment patterns between the institutions; however, in the latter analysis, site (Institution 1 compared with Institution 2) was modeled as the outcome variable. Owing to the inclusion of multiple feet from the same subjects, a generalized estimating equation was used to account for the clustering effect.

Because of the high proportion of patients undergoing surgery at Institution 1, a time-to-event analysis was used to better understand factors that were predictive of major surgery. Univariate Cox proportional hazards regression analyses of time to major surgery were used to identify variables significantly associated with the risk of major surgery. The absence of a percutaneous tenotomy $(\mathrm{p}=$ 0.027 ), increased number of casts $(p<0.001)$, number of revision casts $(\mathrm{p}=0.001)$, number of cast-related complications $(p=0.005)$, and the number of different providers who performed castings (three or four vs one; $p=0.019$ ) (Supplemental Fig. 1. Supplemental material is available with the online version of $\mathrm{CORR}^{\circledR}$.) were significantly associated with the risk of major surgery. An increase in the number of brace visits in which noncompliance was 
Table 1. Patient demographics and treatment patterns at the two institutions

\begin{tabular}{|c|c|c|c|}
\hline Variable & Institution 1 & Institution 2 & $\mathrm{p}$ value* \\
\hline \multicolumn{4}{|l|}{ Demographics } \\
\hline Female sex, number $(\%)$ & $30(23 \%)$ & $27(30 \%)$ & 0.493 \\
\hline English as primary parental language & $112(86 \%)$ & $91(100 \%)$ & $<0.001$ \\
\hline Positive family history, number (\%) & $32(29 \%)$ & $29(35 \%)$ & 0.588 \\
\hline Perinatal complications, number (\%) & $15(11 \%)$ & $10(11 \%)$ & 0.901 \\
\hline Average birth weight, mean (SD) & $8 \pm 4$ & $7 \pm 2$ & 0.003 \\
\hline \multicolumn{4}{|l|}{ Treatment patterns } \\
\hline Noncompliance during bracing, number (\%) & $48(42 \%)$ & $11(12 \%)$ & $<0.001$ \\
\hline Underwent tenotomy, number (\%) & $86(66 \%)$ & $89(98 \%)$ & $<0.001$ \\
\hline \multicolumn{4}{|l|}{ Complication noted during a cast visit } \\
\hline None, number $(\%)$ & $82(63 \%)$ & $89(98 \%)$ & $<0.001$ \\
\hline Once, number $(\%)$ & $27(21 \%)$ & $2(2 \%)$ & \\
\hline Multiple, number (\%) & $22(17 \%)$ & $0(0)$ & \\
\hline \multicolumn{4}{|l|}{ Number of revision casts } \\
\hline None, number (\%) & $94(82 \%)$ & $74(81 \%)$ & 0.617 \\
\hline Once, number $(\%)$ & $7(6 \%)$ & $3(3 \%)$ & \\
\hline Multiple, N (\%) & $13(11 \%)$ & $14(1 \%)$ & \\
\hline Number of casts, mean (SD) & $8 \pm 3$ & $4 \pm 1$ & $<0.001$ \\
\hline Days between casts, mean (SD) & $8 \pm 2$ & $9 \pm 2$ & 0.002 \\
\hline
\end{tabular}

* Based on generalized logistic regression analysis.

documented ( $\mathrm{p}=0.062$ ) was not significant at $\mathrm{p}$ less than 0.05 , but was considered for inclusion in the multivariate analysis. Patient sex $(\mathrm{p}=0.835)$, parental language $(\mathrm{p}=$ $0.525)$, family history $(\mathrm{p}=0.653)$, perinatal complications $(\mathrm{p}=0.114)$, number of days between cast visits $(\mathrm{p}=0.513)$, and birth weight $(\mathrm{p}=0.163)$ were not significantly associated with the risk of major surgery (Supplemental Table 1. Supplemental material is available with the online version of $\operatorname{CORR}^{\circledR}$.). A multivariate Cox proportional hazards regression analysis then was used to examine the simultaneous effect of all factors identified as significant $(\alpha$ $<0.100)$ in the univariate analysis. Using a stepwise method for selecting the final model, an $\alpha$ cutoff level less than 0.050 was required for a factor to remain in the final model. To account for the correlation of bilateral legs, the robust method, as described by Lin and Wei [18], of estimating the covariance matrix was used.

\section{Results}

The proportion of patients undergoing unplanned deviations in routine postcasting followup care was much lower at the institution that adhered rigidly to the principles of Ponseti casting (Institution 2) than at the one that used variable approaches to clubfoot cast treatment (Institution 1). The probability of major surgery was $47 \%$ (30 of 131) at Institution 1 compared with $2 \%$ (two of 91) at Institution
2 (odds ratio [OR] 51.1; 95\% CI, 6.8-384.0; $\mathrm{p}<0.001$ ) (Fig. 1). However, there was no difference (13\%, 11 of 91 , vs $7 \%$, nine of 131) in the occurrence of minor recurrences only (repeat casting, repeat tendo Achilles lengthening, and/or anterior tibialis tendon transfer) between the institutions (OR, 0.5; 95\% CI, 0.19-1.4; p = 0.200) (Fig. 1).

At the institution that did not adhere rigidly to Ponseti's principles, revision casting and an increase in the number of cast complications were associated with an increased likelihood of major surgery in the multivariate analysis. After adjusting for the number of revision casts during bracing, the risk of major surgery among patients who had multiple cast-related complications was 2.8 times $(95 \% \mathrm{CI}$, $1.2-6.7 ; \mathrm{p}=0.019)$ the risk of major surgery among patients who did not have any cast-related complications. After adjusting for cast-related complications, the risk of major surgery among patients who underwent multiple revision casts was 3.9 times (95\% CI, 2.0-7.6; p < 0.001) the risk of major surgery among patients who did not undergo revision casting.

\section{Discussion}

Clubfoot is a three-dimensional musculoskeletal deformity characterized by equinus, hindfoot varus, and forefoot adductus and cavus [25]. In ambulatory children, the deformity causes the child to walk on the lateral border and 


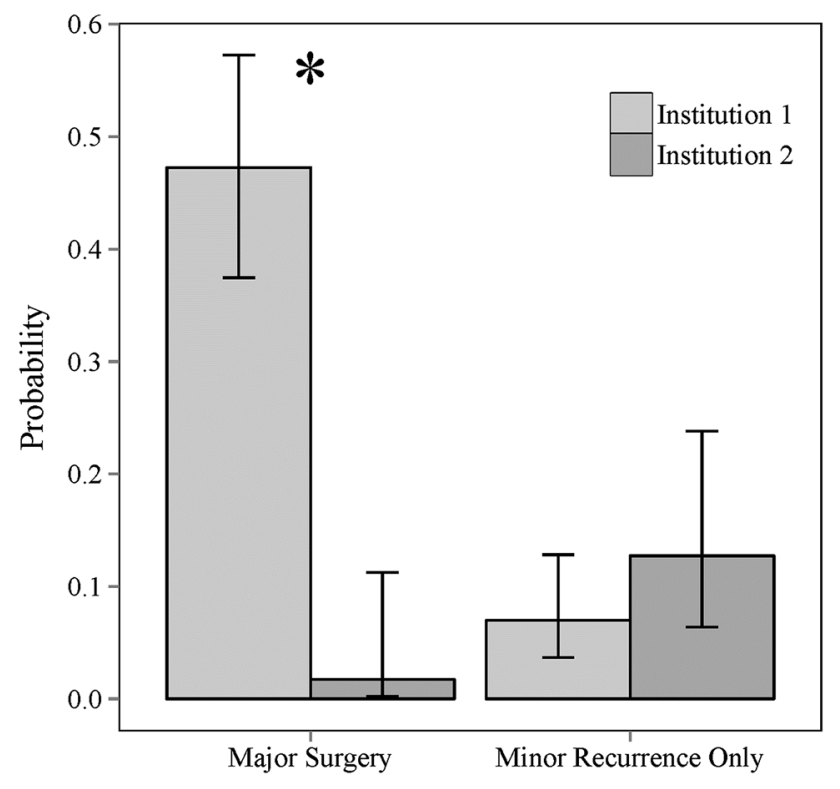

Fig. 1 The probability of treatment failure at the two institutions is shown.

when severe, the dorsum of their foot. If untreated, this compromised foot position can result in severe disability with long-term sequelae [23]. Popular treatment options include primary soft tissue release surgery and the Ponseti method of clubfoot manipulation and serial casting [7, 12, 13]. The Ponseti method is associated with fewer surgical revisions [12], decreased cost [13], and most importantly, better long-term functional outcomes compared with primary soft tissue release surgery [16]. However, the Ponseti method has been used with varying degrees of success across institutions [3, 8-12, 15, 17, 21, 24, 26, 28, 33]. The purpose of our study was to compare conservative treatment patterns for isolated clubfoot at two institutions: Institution 1, with multiple providers using a nonuniform Ponseti treatment approach, and Institution 2, with a single provider dedicated to the Ponseti method. We found that rigid adherence to Ponseti's principles was associated with a decreased likelihood of unplanned surgical intervention beyond repeat tendo Achilles lengthening and/or anterior tibialis tendon transfer.

We recognize several main limitations. The occurrence of unplanned deviations from routine postoperative cast care was the primary endpoint of interest. In the absence of patient-reported, functional outcome measures, increased risk of surgery beyond a repeat tendo Achilles lengthening and/or anterior tibialis tendon transfer should not be interpreted as an increased risk of a poor functional outcome. Clubfoot surgery following casting is ultimately an elective procedure. Differences in the thresholds for recommending surgery after deformity recurrence between institutions may have accounted for the large difference in the proportion of feet that underwent unplanned surgery beyond a repeat tendo Achilles lengthening and/or anterior tibialis tendon transfer at Institution 1 compared with Institution 2. The proportion of patients who were followed for more than 2 years was greater at Institution $2(100 \%, 58$ of 58) than Institution 1 (68\%, 91 of 133). This potential transfer bias may have resulted in an underestimation (if patients who were lost to followup were more likely to undergo surgery) or an overestimation (if patients who were lost to followup were less likely to undergo major surgery) of the rate of major surgery at Institution 1.

An objective measure of clubfoot severity, such as the method of Dimeglio et al. [6], was not available. It is possible that the overall severity of clubfeet treated may have differed between the two institutions thereby confounding results. Additionally, it is possible that the single surgeon at Institution 2 was exceptionally skilled, and thus differences in treatment outcomes between institutions may not be completely modifiable. The care provided at Institution 2 is representative of a high level of care. However, the success of the Ponseti method reported from centers around the world provides strong evidence that the technique can be replicated. Finally, data were collected retrospectively. It is possible that variables such as cast complications and bracing complications were underreported. This misclassification has potential to bias the results if the misclassification was related to study site and treatment failure.

The difference in the proportion of patients who underwent major surgery at the two institutions included in the study reflects the variability in treatment outcomes reported by others. Among studies with a mean followup between 18 months and 5 years, the proportion of patients with recurrence of deformity ranges between $10 \%$ and $41 \%$ $[3,8-12,15,17,21,24,26,28,33]$. At Institution 1, the probability (46\%) of major surgery resembled surgery rates for conservative, isolated clubfoot treatment approaches, which are similar to but not committed to the Ponseti technique [5, 14, 32]. In contrast, the low probability $(1.7 \%)$ of major surgery at Institution 2 , is reflective of other similar cohorts $[21,22,27]$ in which less than $15 \%$ of patients treated with the Ponseti method undergo major surgery. Such wide variability in the use of major surgery in the treatment of clubfoot is costly and burdensome on the patient and the healthcare system [12, 13]; therefore, there is a strong need to identify factors that are driving the increased variability in surgical rates.

There was no difference in the proportion of patients who had a minor recurrence only (treated with revision casting, repeat tendo Achilles lengthening, and/or anterior tibialis tendon transfer) at Institution $2(19 \%)$ compared with Institution 1 (18\%). This suggests that Institution 2 may have been more proactive in the treatment of isolated clubfoot relapses. Commitment to the Ponseti conservative 
treatment method, including aggressive repeat casting to address relapses, is likely to improve our ability to identify recurrences that will respond to repeat casting compared with those that undergo surgical intervention.

The two most important predictors of major surgery at Institution 1 were revision casting during bracing and the development of cast-related complications. As revision casting is indicative of a minor recurrence, it is not surprising that revision casting was strongly predictive of major surgery. During the initial casting phase of treatment, the risk of major surgery among patients who had multiple cast-related complications was 2.8 times the risk of major surgery among patients who did not have any complications. The development of cast-related complications often mandated time off from casting until the complication resolved. As a result, cast-related complications disrupted the continuity of the casting period and increased the duration of time spent in the initial casting phase of treatment.

The relationship between deviations from the Ponseti method and an increased likelihood of treatment failure is supported in current literature. Bor et al. [2] observed that deviations from the Ponseti bracing recommendations were associated with a near twofold increase in additional operations. Excessive weight gain [4], parental educational level $[8,12]$, a positive family history $[8,12]$, and bracing noncompliance $[8,9,11,21,28,31]$ have been identified as patient-related predictors of treatment failure.

With conservative management of isolated clubfoot, rigid commitment to the Ponseti method without variation appears to yield a lower likelihood of a patient undergoing major clubfoot surgery. Our data also suggest that the presence of a single provider coordinating care in a clubfoot program can result in a low occurrence of major surgical events-a common factor in previous studies reporting a low incidence of major clubfoot surgery after Ponseti casting $[21,22,27]$. Establishment of a clubfoot program requires a care coordinator, dedicated cast technicians and orthotists, a team commitment among providers, and emphasis on continuity of care. For optimal results and avoidance of major surgery, adherence to the principles of the Ponseti method is essential. This requires a substantial investment from the providers and institution in terms of ensuring an adequate level of training and designated clinic time. Finally, the clubfoot program should emphasize the importance of providing a support system for parents throughout this demanding treatment process.

\section{References}

1. Aronson J, Puskarich CL. Deformity and disability from treated clubfoot. J Pediatr Orthop. 1990;10:109-119.
2. Bor N, Coplan JA, Herzenberg JE. Ponseti treatment for idiopathic clubfoot: minimum 5-year followup. Clin Orthop Relat Res. 2009;467:1263-1270.

3. Changulani M, Garg NK, Rajagopal TS, Bass A, Nayagam SN, Sampath J, Bruce CE. Treatment of idiopathic club foot using the Ponseti method: initial experience. J Bone Joint Surg $\mathrm{Br}$. 2006;88:1385-1387.

4. Cooper DM, Dietz FR. Treatment of idiopathic clubfoot: a thirtyyear follow-up note. J Bone Joint Surg Am. 1995;77:1477-1489.

5. Crawford AH, Gupta AK. Clubfoot controversies: complications and causes for failure. Instr Course Lect. 1996;45:339-346.

6. Dimeglio A, Bensahel H, Souchet P, Mazeau P, Bonnet F. Classification of clubfoot. J Pediatr Orthop B. 1995;4:129-136.

7. Dobbs MB, Gurnett CA. Update on clubfoot: etiology and treatment. Clin Orthop Relat Res. 2009;467:1146-1153.

8. Dobbs MB, Rudzki JR, Purcell DB, Walton T, Porter KR, Gurnett CA. Factors predictive of outcome after use of the Ponseti method for the treatment of idiopathic clubfeet. J Bone Joint Surg Am. 2004;86:22-27.

9. Goksan SB, Bursali A, Bilgili F, Sivacioglu S, Ayanoglu S. Ponseti technique for the correction of idiopathic clubfeet presenting up to 1 year of age: a preliminary study in children with untreated or complex deformities. Arch Orthop Trauma Surg. 2006;126:15-21.

10. Gupta A, Singh S, Patel P, Patel J, Varshney MK. Evaluation of the utility of the Ponseti method of correction of clubfoot deformity in a developing nation. Int Orthop. 2008;32:75-79.

11. Haft GF, Walker CG, Crawford HA. Early clubfoot recurrence after use of the Ponseti method in a New Zealand population. $J$ Bone Joint Surg Am. 2007;89:487-493.

12. Halanski MA, Davison JE, Huang JC, Walker CG, Walsh SJ, Crawford HA. Ponseti method compared with surgical treatment of clubfoot: a prospective comparison. J Bone Joint Surg Am. 2010;92:270-278.

13. Halanski MA, Huang JC, Walsh SJ, Crawford HA. Resource utilization in clubfoot management. Clin Orthop Relat Res. 2009;467:1171-1179.

14. Harrold AJ, Walker CJ. Treatment and prognosis in congenital club foot. J Bone Joint Surg Br. 1983;65:8-11.

15. Herzenberg JE, Radler C, Bor N. Ponseti versus traditional methods of casting for idiopathic clubfoot. J Pediatr Orthop. 2002;22:517-521.

16. Ippolito E, Farsetti P, Caterini R, Tudisco C. Long-term comparative results in patients with congenital clubfoot treated with two different protocols. J Bone Joint Surg Am. 2003;85:1286-1294.

17. Janicki JA, Narayanan UG, Harvey BJ, Roy A, Weir S, Wright JG. Comparison of surgeon and physiotherapist-directed Ponseti treatment of idiopathic clubfoot. J Bone Joint Surg Am. 2009;91:1101-1108.

18. Lin DY, Wei LJ. The robust inference for the Cox proportional hazards model. J Am Stat Assoc. 1989;84:1074-1079.

19. Martin JA, Hamilton BE, Ventura SJ, Menacker F, Park MM. Births: final data for 2000. Natl Vital Stat Rep. 2002;50:1-101.

20. Morcuende JA. Congenital idiopathic clubfoot: prevention of late deformity and disability by conservative treatment with the Ponseti technique. Pediatr Ann. 2006;35:128-130, 132-136.

21. Morcuende JA, Dolan LA, Dietz FR, Ponseti IV. Radical reduction in the rate of extensive corrective surgery for clubfoot using the Ponseti method. Pediatrics. 2004;113:376-380.

22. Ponseti IV. Treatment of congenital club foot. J Bone Joint Surg Am. 1992;74:448-454.

23. Ponseti IV. Congenital Clubfoot: Fundamentals ofTtreatment. Oxford, UK: Oxford University Press; 1996.

24. Ponseti IV, Zhivkov M, Davis N, Sinclair M, Dobbs MB, Morcuende JA. Treatment of the complex idiopathic clubfoot. Clin Orthop Relat Res. 2006;451:171-176. 
25. Radler C. The Ponseti method for the treatment of congenital club foot: review of the current literature and treatment recommendations. Int Orthop. 2013;37:1747-1753.

26. Richards BS, Faulks S, Rathjen KE, Karol LA, Johnston CE, Jones SA. A comparison of two nonoperative methods of idiopathic clubfoot correction: the Ponseti method and the French functional (physiotherapy) method. J Bone Joint Surg Am. 2008;90:2313-2321.

27. Shack N, Eastwood DM. Early results of a physiotherapistdelivered Ponseti service for the management of idiopathic congenital talipes equinovarus foot deformity. J Bone Joint Surg Br. 2006;88:1085-1089.

28. Thacker MM, Scher DM, Sala DA, van Bosse HJ, Feldman DS, Lehman WB. Use of the foot abduction orthosis following Ponseti casts: is it essential? J Pediatr Orthop. 2005;25:225228 .

29. Tindall AJ, Steinlechner CW, Lavy CB, Mannion S, Mkandawire $\mathrm{N}$. Results of manipulation of idiopathic clubfoot deformity in
Malawi by orthopaedic clinical officers using the Ponseti method: a realistic alternative for the developing world? J Pediatr Orthop. 2005;25:627-629.

30. United States Census Bureau. Annual Estimates of the Resident Population for Counties: April 1, 2010 to July 1, 2014. Available at: http://www.census.gov/popest/data/counties/totals/2014/COEST2014-01.html. Accessed July 6, 2015.

31. Willis RB, Al-Hunaishel M, Guerra L, Kontio K. What proportion of patients need extensive surgery after failure of the Ponseti technique for clubfoot? Clin Orthop Relat Res. 2009;467:12941297.

32. Yamamoto H, Muneta $\mathrm{T}$, Morita S. Nonsurgical treatment of congenital clubfoot with manipulation, cast, and modified Denis Browne splint. J Pediatr Orthop. 1998;18:538-542.

33. Zwick EB, Kraus T, Maizen C, Steinwender G, Linhart WE. Comparison of Ponseti versus surgical treatment for idiopathic clubfoot: a short-term preliminary report. Clin Orthop Relat Res. 2009;467:2668-2676. 